\title{
Strategi Ekstrakurikuler Muhadharah dalam Melatih Kemampuan Public Speaking Siswa Mi
}

\author{
Erfan Dwi Santoso'), Rizki Amalia Sholihah²), Yafita Arfina Mu'ti3) \\ 13) Institut Agama Islam Sunan Giri Ponorogo \\ ${ }^{2)}$ Institut Agama Islam Negeri Ponorogo \\ E-mail: yafitaarfina@gmail.com, rizkiamalias@iainponorogo.ac.id
}

\begin{abstract}
This study aims to determine the implementation of Muhadharah in training public speaking skills at MI Ruhul Amin, Muhadharah's extracurricular strategies in training public speaking skills, and its inhibiting and supporting factors. This type of research was conducted in the form of a qualitative descriptive field study. This study's sources of data include principals, teachers, students, and non-human data sources consisting of relevant madrasah documents and data. The results showed that the extracurricular activities of Muhadharah at MI Ruhul Amin were held every Saturday afternoon. The strategy used is to make a muhadharah schedule, compile and correct the speech's text, take turns choosing a place for muhadharah, take part in competitions or competitions. Inhibiting factors include students' lack of interest in muhadharah practice, lack of confidence, incomplete facilities, students' different character, and monotonous material delivery. These supporting factors include the extracurricular muhadharah that is carried out regularly, the existence of learning evaluations, the existence of sanctions for students who violate the rules, and quality supervisors.
\end{abstract}

Keywords:

extracurricular, madrasah ibtidaiyah, muhadharah, public speaking, strategy

\section{A. PENDAhuluan}

Di era globalisasi ini telah terjadi perubahan drastis yang terjadi di seluruh dunia. Perubahan yang luar biasa ini terjadi ketika orang memiliki keinginan yang kuat untuk mencapai sesuatu. Keinginan orang terpenuhi ketika mereka mengekspresikan ide dan pendapat mereka dengan jelas kepada orang lain. Oleh karena itu, mereka perlu mempelajari keterampilan komunikasi untuk memenuhi ambisi, keinginan, dan tujuan mereka ${ }^{1}$. Di dunia modern ini, keterampilan komunikasi memainkan peran penting dan seseorang harus memiliki penguasaan atas keterampilan tersebut untuk mendapatkan

1 Parupalli Rao Srinivas, "The Importance of Speaking Skills in English Classrooms," Alford Council of International English \& Literature Journal(ACIELJ) Vol 2, no. Issue 2 (2019): 18. kesuksesan di bidangnya masingmasing. Jadi, berbicara adalah keterampilan terpenting di antara keempat keterampilan bahasa agar dapat berkomunikasi dengan baik di dunia global ini ${ }^{2}$. Untuk mencapai keberhasilan berbicara di depan umum maka diperlukan adanya pengembangan potensi peserta didik sejak dini salah satunya melalui kegiatan ekstrakurikuler dengan kegiatan muhadharah.

Muhadharah merupakan latihan pidato atau ceramah guna mendidik para siswa agar terampil dan mampu berbicara di depan umum (public speaking) untuk menyampaikan ajaran-

\footnotetext{
${ }^{2}$ Rizki Amalia Sholihah, "Metode Suggestopedia Dengan Teknik Bermain Peran Atau Role Playing Dalam Pembelajaran Keterampilan Berbicara Bahasa Indonesia Siswa Sekolah Dasar," AlAdabiya: Jurnal Kebudayaan Dan Keagamaan 10, no. 1 (2017): 1-24.
} 
ajaran Islam di hadapan umum dengan penuh percaya diri. Kegiatan Muhadharah di MI Ruhul Amin dilakukan setiap hari sabtu pada jam terakhir pembelajaran yang diikuti oleh seluruh siswa (kelas 1-6) yang berkumpul di satu ruangan. Kegiatan Muhadharah ini diharakan mampu melatih dan meningkatkan kedisiplinan, rasa percaya diri, dan tanggungjawab siswa Namun dalam pelaksanaanya juga terdapat beberapa masalah di antaranya adalah ternyata ada sebagian siswa yang sulit untuk mengikuti ekstrakurikuler tersebut dengan berbagai alasan. Di samping itu terdapat juga beberapa siswa terkadang terlihat kurang antusias dalam mengikuti kegiatan ekstrakurikukuler ini, seperti ketika diberi tugas siswa tersebut tidak mau ataupun tampil dengan kurang memuaskan. Hal itu disebabkan karena siswa malas dan bisa juga karena siswa kurang percaya diri dengan kemampuan yang dimiliki.

Beberapa penelitian terdahulu mengenai muhadharah di antaranya meningkatakan kemampuan komunikasi 3, melatih kecerdasan linguistik 4 , meningkatakan kepercayaan diri 5. Penelitian lain mengenai public spreaking yaitu pada para pemuda ${ }^{6}$, melatih kepercayaan

\footnotetext{
${ }^{3}$ Azimah Kusuma Ati, "Peran Muhadharah Dalam Melatih Kemampuan Komunikasi Siswa Di Mi Ma'arif Polorejo Babadan Ponorogo" (IAIN Ponorogo, 2020).

4 Lina Purwanti, "Problematika Peningkatan Kecerdasan Linguistik Siswa Dalam Kegiatan Muhadharah (Studi Kasus Di MI Ma'arif Polorejo Ponorogo)" (IAIN Ponorogo, 2020).

5 Wahyu Binti Nurohmah Dian, "PERAN GURU DALAM MENINGKATKAN PERCAYA DIRI SISWA MELALUI KEGIATAN EKSTRAKURIKULER MUHADHARAH DI MI MA'ARIF AL ISHLAH KALISAT BUNGKAL PONOROGO" (IAIN PONOROGO, 2018).

6 Tamrin Fathoni et al., "Upaya Peningkatan Kemampuan Public Speaking Pemuda Sragi
}

diri anak SD 7 dan pada anak-anak sanggar kesenian ${ }^{8}$. Penelitian lain yang sejenis yaitu membahas mengenai keefektifan ekstrakurikuler Muhadharah pada siswa MA 9, keterampilan berbicara mahasiswa ${ }^{10}$, dan public speaking pada santri pondok pesantren " ${ }^{11}$. Persamaan penelitian terdahulu dengan peneliti adalah terkait dengan kegiatan ekstrakurikuler muhadharah. Perbedaannya adalah terdapat pada tempat dan variabel penelitian. Tempat pelaksanaan penelitian terdahulu adalah di sebuah madrasah aliyah dengan variabel penelitian tentang pembentukan rasa percaya diri, sedangkan tempat penelitian ini dilakukan di sebuah madrasah ibtidaiyah dengan variabel membentuk kemampuan public speaking.

Muhadharah berasal dari kata

Ponorogo," Amalee: Indonesian Journal of Community Research and Engagement 2, no. 1 (2021): 23-32.

7 Unggul Priyadi, "MEMBANGUN KEPERCAYAAN DIRI ANAK MELALUI PELATIHANPUBLIC SPEAKING GUNA PERSIAPKAN GENERASI BERKARAKTER," Asian Journal of Innovation and Entrepreneurship 2, no. 02 (2013): 88-93.

${ }^{8}$ Prita S Nurcandrani, Bunga Asriandhini, and Ade Tuti Turistiati, "Pelatihan Public Speaking Untuk Membangun Kepercayaan Diri Dan Keterampilan Berbicara Pada Anak-Anak Di Sanggar Ar-Rosyid Purwokerto," Jurnal Abdi MOESTOPO 3, no. 01 (2020): 27-32.

9 Noris Firmansyah, "Efektivitas Kegiatan Ekstrakurikuler Muhadharah Dalam Pembentukan Rasa Percaya Diri Peserta Didik MA Fadllillah Tambak Sumur Waru Sidoarjo" (UIN Sunan Ampel Surabaya, 2017).

10 Rizki Amalia Sholihah, "Praktik Pembelajaran Keterampilan Berbicara Di Masa Pandemi Covid19," NATURALISTIC: Jurnal Kajian Penelitian Pendidikan Dan Pembelajaran 5, no. 1 (2020): 70517, https://doi.org/10.35568/naturalistic.v5i1.977.

11 Loviana Adela, "Strategi Pelatihan Muhadharah Terhadap Kemampuan Berdakwah Santri Pondok Pesantren Darul Ulya Iringmulyo Kecamatan Metro Timur Kota Metro Lampung” (IAIN Metro, 2019). 
yang berarti hadir, sebagai mashdar mim menjadi محاضرة yang artinya ceramah atau pidato. Puidato sendiri dimaknai sebagai sebagai pidato, yakni pengungkaan pemikiran berupa kata-kata kepada orang banyak atau wacana yang disiapkan untuk diucapkan di khalayak, dengan tujuan agar pendengarnya mengetahui, memahami, menerima, serta diharapkan bersedia melaksanakan segala sesuatu yang telah disampaikan kepada mereka ${ }^{12}$. Tujuan dari pidato atau muhadharah di antaranya yaitu ingin menyampaikan pesan dan informasi, mendidik, mengibur, membujuk dan menarik perhatian ${ }^{13}$. Dalam kegiatan ekstrakurikuler muhadharah,perlu adanya strategi yang digunakan guna menunjang keberhasilan dalam pelaksanaanya. Terdapat beberapa strategi yang dapat dilakukan yaitu strategi langsung, strategi naskah, strategi hafalan, dan strategi variatif (Bashori el al., 2018).

Public speaking atau yang dikenal dengan seni berbicara di depan umum atau juga seni retorika, mempunyai tujuan yang sama dengan muhadharah atau berpidato yaitu ingin menyampaikan sebuah maksud dan diharapkan setelah tersampaikannya maksud tersebut, pendengar akan mengikuti apa yang disampaikan oleh pembicara ${ }^{14}$. Public speaking merupakan bagian kehidupan sosial umat manusia dimana mereka saling

\footnotetext{
12 Hadi Rumpoko, Panduan Pidato Luar Biasa (Yogyakarta: Mega Books, 2012).

13 Nur Ainiyah, "PEMBERDAYAAN KETERAMPILAN RETORIKA DAKWAH SANTRI PONDOK PESANTREN MIFTAHUL ULUM PANDEAN WONOREJO BANYUPUTIH SITUBONDO," As-Sidanah: Jurnal Pengabdian Masyarakat 1, no. 2 (2019): 141-70.

14 Saifudin Zuhri, Public Speaking (Yogyakarta: Graha Ilmu, 2010).
}

berkomunikasi satu sama lain dalam suatu kesempatan atau forum-forum tertentu (Bashori et al., 2018). Terdapat beberapa jenis public speaking di antaranya adalah khutbah, propaganda, kampanye, penerangan, agitasi, orasi ilmiah, dan reportase. Berdasar latar belakang masalah tersebut, penulis melakukan penelitian mengenai "Strategi Ekstrakurikuler Muhadharah dalam Melatih Kemampuan Public speaking Siswa di MI Ruhul Amin Temon Sawoo Ponorogo tahun ajaran 2019/2020 guna mengetahui implementasi Muhadharah dalam melatih keterampilan berbicara di depan umum di MI Ruhul Amin, strategi ekstrakurikuler Muhadharah dalam melatih keterampilan berbicara di depan umum, dan faktor penghambat dan pendukungnya.

\section{B. METODE}

Penelitian ini menggunakan pendekatan kualitatif (Qualitative Reseach) dimana ditunjukkan untuk mendeskripsikan dan menganalisis masalah sosial atau masalah manusia ${ }^{15}$. Dalam penelitian ini masalah sosial yang diteliti adalah strategi yang digunakan oleh guru dalam pelaksanaan kegiatan ekstrakurikuler muhadharah beserta faktor yang menghambat dan pendukungnya.

Penelititian ini dilakukan di MI Ruhul Amin Desa Temon Kecamatan Sawoo kabupaten Ponorogo. Sumber data dalam penelitian ini yaitu kepala sekolah, guru dan siswa di MI Ruhul Amin kelas 4-6 yang melaksanakan kegiatan ekstrakurikuler. Data dikumpulkan dengan observasi, wawancara, dan dokumentasi.

\footnotetext{
15 Farida Nugrahani, Metode Penelitian Kualitatif Dalam Penelitian Pendidikan Bahasa, Cakra Book (Solo, 2014).
} 
Nantinya data hasil penelitian akan dianalisis dengan tiga langkah yaitu reduksi data, penyajian data dalam bentuk uraian, dan menarik kesimpulan-kesimpulan tentang internalisasi nilai-nilai nasionalisme ${ }^{16}$. Penyajian hasil penelitian berupa paparan secara deskriptif.

\section{HASIL DAN PEMBAHASAN}

\section{Hasil}

a. Pelaksanaan Kegiatan

Ekstrakurikuler Muhadharah di MI Ruhul Amin

Dari hasil wawancara peneliti dengan kepala sekolah MI Ruhul Amin Bapak Ahmad Roh Aminanto tentang pelaksanaan ekstrakurikuler muhadharah di MI Ruhul Amin dilaksanakan rutin setiap hari sabtu pukul 11:0o - 12:00 WIB yang diikuti oleh semua siswa dari kelas satu sampai dengan kelas enam. Acara dimulai dari pembukaan, pembacaan ayat suci Al-Qur'an, menyanyikan mars madrasah, pidato, hiburan, sambutan dan penutup.

Pelaksanaan muhadharah dilakukan dengan tiga bahasa yaitu bahasa Indonesia, bahasa Inggris, bahasa Arab, pembimbing memilih petugas pada waktu sambutan. Dalam pelaksanaanya kelas satu sampai tiga hanya sebagai peserta sedangkan petugasnya kelas empat sampai enam. Materi pidato diambil dari buku-buku latihan pidato di perpustakaan dan juga dari internet.

Tujuan dari kegiatan ekstrakurikuler muhadharah

16 Sugiyono, Metode Penelitian Pendidikan: (Pendekatan Kuantitatif, Kualitatif Dan $R \& D$ ) (Bandung: Alfabeta, 2008). adalah untuk melatih siswa untuk berani tampil depan orang banyak dan melatihh tanggung jawab. Selain itu diharapkan dengan adanya ekstrakurikuler muhadharah siswa mendapatkan pengetahuan lebih tentang ilmu bahasa. Karena dalam ekstrakurikuler muhadharah terdapat tiga macam bahsa yang digunakan yaitu; Bahasa Indonesia, Bahasa Arab dan bahasa Jawa. Dengan susunan acara dan petugas sebagai berikut:

1. Pembukaan

2. Pembacaan ayat suci Al-Qur'an

3. Menyanyikan mars MI

4. Pidato-pidato

5. Hiburan

6. Sambutan muhadharah

pembimbing

7. Penutup

\begin{tabular}{|l|l|l|}
\hline No. & $\begin{array}{l}\text { Jumlah } \\
\text { siswa }\end{array}$ & Tugas \\
\hline 1. & 1 orang & Bertugas sebagai MC \\
\hline 2. & 1 orang & $\begin{array}{l}\text { Bertugas sebagai } \\
\text { Pembacaan ayat suci } \\
\text { Al-Qur'an }\end{array}$ \\
\hline 3. & 1 orang & $\begin{array}{l}\text { Bertugas } \\
\text { dirijen }\end{array}$ \\
\hline 4. & $\begin{array}{l}\text { f menjadi } \\
\text { orang }\end{array}$ & $\begin{array}{l}\text { Bertugas membawakan } \\
\text { pidato }\end{array}$ \\
\hline $5 \cdot$ & 5 orang & $\begin{array}{l}\text { Bertugas untuk } \\
\text { menampilkan hiburan }\end{array}$ \\
\hline
\end{tabular}

b. Strategi ekstrakurikuler muhadharah dalam melatih kemampuan public speaking siswa di MI Ruhul Amin

Dalam kegiatan pelatihan muhadharah tidak terlepas dari adanya strategi yang digunakan agar pelatihan muhadharah berjalan secara maksimal. Dengan 
strategi perencanaan yang matang mampu menghasilkan kegiatan muhadharah yang menyenangkan dan dapat berjalan secara optimal. Strategi yang digunakan di MI Ruhul Amin adalah sebagai berikut:

1. Pembuatan jadwal muhadharah

Dengan strategi pembuatan jadwal kegiatan muhadharah akan terlaksana dengan terstruktur. Karena siswa tidak hanya belajar satu bahasa saja tetapi tiga bahasa sekaligus yang dapat dipelajari.

2. Membuat dan mengoreksi teks pidato

Dengan strategi ini siswa dituntut untuk membuat naskah pidato dan mengoreksikannya kepada pembimbing tujuannya agar siswa dalam penyampaian isi pidato tidak ragu-ragu dan menggunakan metode dan bahasa yang baik dan benar.

3. Pemilihan tempat muhadharah secara bergantian

Dalam pelaksanaan muhadharah di MI Ruhul Amin tempatnya berubah-ubah dari kelas satu pada minggu pertama lalu kelas dua dan terus bergantian sampai nanti kembali ke kelas satu. Dengan strategi ini diharapkan siswa tidak merasa bosan karena tempatnya selalu berganti-ganti.

4. Pengikutan kompetisi atau lomba.

Untuk menambah semangat siswa dalam mengikuti kegiatan ekstrakurikuler muhadharah MI Ruhul Amin memberikan sebuah kesempatan kepada siswa yang berlatih dengan baik ketika

ekstrakurikuler

muhadharah akan

diikutsertakan dalam lombalomba pidato. Dengan itu siswa diharapkan untuk lebih sungguh-sungguh dalam kegiatan ekstrakurikuler muhadharah.

Dalam pelaksanaanya metode yang digunakan adalah metode hafalan juga dengan membaca teks tergantung tingkat kelas.

c. Faktor penghambat dan pendukung dalam kegiatan ektrakurikuler muhadharah dalam melatih kemampuan public speaking siswa di MI Ruhul Amin Menurut wawancara dengan kepala sekolah MI Ruhul Amin terdapat beberapa faktor penghambat dan pendukung dalam kegiatan tersebut yaitu:

1. Faktor penghambat

a. Kurangnya minat siswa dalam pelatihan muhadharah Tidak semua siswa di MI Ruhul Amin memiliki semangat yang tinggi, ada yang dari awal sampai akhir sangat bersemangat, ada yang hanya semangat diawal, dan ada juga yang malasmalasan. Siswa yang seperti ini membutuhkan perhatian yang lebih, diberi nasihat, bimbingan dan arahan oleh para ustadzah agar lebih bersemangat dalam kegiatan ekstrakurikuler muhadharah.

b. Kurang kuatnya mental siswa Siswa yang mengikuti ekstrakurikuler muhadharah dengan tujuan untuk melatih mental para siswa, siswa yang masih belum pandai berbicara di depan umum 
atau kurang percaya diri adalah siswa yang baru diberi tugas menjadi petugas ekstrakurikuler muhadharah. Untuk siswa yang kelas lima dan enam kebanyakan sudah terbiasa untuk tampil di depan umum. Maka dari itu para pembimbing muhadharah wajib untuk mengajarkan teknik berpidato dengan langkah demi langkah dan membutuhkan kesabaran khusus berbeda dengan melatih siswa yang sudah lama menjadi petugas muhadharah.

c. Sarana yang kurang lengkap Dalam setiap kegiatan tentunya membutuhkan sarana yang memadai ataupun bisa dibilang lengkap agar suatu kegiatan dapat berjalan secara maksimal. Begitu pula dengan muhadharah juga membutuhkan sarana dan prasarana yang memadai, salah satunya adalah pengeras suara/microfon. Dengan pengeras suara audiens bisa mendengar secara jelas.

d. Karakter siswa yang berbedabeda

Setiap anak mempunyai karakteristik yang berbedabeda. Ini membutuhkan perhatian yang lebih agar perbedaan tersebut tidak menimbulkan sebuah permasalahan. Dengan tidak membeda-bedakan antara satu siswa dengan siswa yang lainnya supaya dalam proses belajar mengajar tercipta rasa keharmonisan antara pembimbing muhadharah dan peserta didik. Maka dari itu dibutuhkan kesabaran khusus bagi para pembimbing untuk berusaha mengajarkan siswa berpidato dengan baik dan benar.

e. Penyampaian materi yang monoton.

Pada kegiatan muhadharah ini juga siswa merasa bosan karena hanya memperhatikan dan mendengarkan apa yang disampaikan pembicara saja apalagi pembicara menyampaikan pidatonya terlalu monoton sehingga mudah membuat siswa menjadi bosan berada diruang muhadharah.

2. Faktor pendukung

a) Ekstrakurikuler muhadharah dilaksanakan secara rutin

Kegiatan yang dilakukan secara terus menerus akan menghasilakan suatu hal yang positif. Dengan diadakannya muhadharah secara rutin pasti siswa akan menjadi terbiasa untuk berani tampil di depan umum.

b) Adanya evaluasi belajar

Pembimbing melatih berpidato tidak hanya pada waktu sebelum tampil, tetapi juga pada saat kegiatan inti telah dilaksanakan, pembimbing memberikan evaluasi terhadap siswa tentang bagaimana hasil kegiatannya, apabila kurang memuaskan atau masih 
terdapat kesalahan maka akan diberitahukan oleh pembimbing serta diperbaiki kesalahannya dengan upaya agar siswa lebih berkembang dan lebih baik kedepannya

c) Adanya hukuman bagi siswa yang melanggar aturan

Agar pelaksanaan ekstrakurikuler muhadharah dapat terlaksana dengan maksimal tentunya juga ada aturan-aturan yang harus ditepati oleh setiap siswa yang mengikuti ekstrakurikuler muhadharah. Jika ada siswa yang melanggar maka akan diberikan sanksi atau hukuman.

d) Pembimbing yang memiliki kualitas.

Pembimbing muhadharah harus mempuyai keahlian khusus pada bidangnya agar siswa yang diajarkan lebih berkembang dan wawasan ilmunya semakin luas. Tidak hanya melalui pengajaran secara langsung, seorang pelatih harus mampu mencontohkan di kehidupan nyata karena siswa juga memperhatikan bagaimana akhlak dan tata krama gurunya dan akan disesuaikan dengan apa yang dipelajarinya

\section{Pembahasan}

Pendidikan merupakan suatu proses yang panjang yang bertujuan untuk membantu manusia menjadi lebih baik dari sebelumnya sehingga membuat perubahan yang lebih baik dari sebelumnya. Pada era modern ini pendidikan tidak hanya dalam segi akademik saja namun harus menggabungkan faktor-faktor lainnya. Seperti halnya faktor kemampuan public speaking, dengan tujuan siswa memiliki kemampuan berbicara di depan umum yang baik untuk bekal dewasa kelak.

MI Ruhul Amin merupakan salah satu madrasah yang banyak kegiatan positif dalam rangka menumbuhkan karakter pada diri siswa di antaranya yaitu melalui program pembelajaran, ekstrakurikuler dan kegiatan pembiasaan.Salah satu kegiatan pembiasaan di MI Ruhul Amin yaitu kegiatan muhadharah. Kegiatan muhadharah merupakan suatu kegiatan siswa dalam berpidato di depan temantemannya. Kegiatan ekstrakurikuler muhadharah di Madrasah Ibtidaiyah Ruhul Amin adalah kegiatan ekstrakurikuler yang wajib diikuti oleh setiap siswa dari kelas satu sampai kelas enam. Namun untuk yang bertugas hanya kelas empat sampai enam saja sedangkan untuk kelas satu sampai tiga sebagai seorang pendengar atau audiens. Pelaksanaan ekstrakurikuler muhadharah di MI Ruhul Amin dilaksanakan setiap hari sabtu pukul 11.00-12.00 siang di dalam satu ruangan. Kegiatan ini bertujuan untuk melatih siswa untuk berani berbicara di depan umum, menumbuhkan rasa percaya diri kedisiplinan dan tanggung jawab.

Susunan acara dalam ekstrakurikuler muhadharah di MI Ruhul Amin dimulai dari pembukaan, pembacaan ayat suci Al-Qur'an, menyanyikan mars MI, penyampaian pidato-pidato, sambutan, hiburan, dan penutup. Untuk pembagian petugas yaitu satu orang bertugas sebagai pembawa acara, satu orang dirijen, satu orang qori' atau pembaca Al-Qur'an, 
empat orang sebagai pengisi acara atau pidato, dan lima orang mengisi hiburan.

Dalam kegiatan ekstrakurikuler muhadharah di MI Ruhul Amin siswa menyusun teks pidato terlebih dahulu kemudian dikumpulkan kepada pembimbing untuk dilakukan pengoreksian terlebih dahulu agar materi yang akan disampaikan ketika berpidato tidak menyimpang dengan pendidikan. Materi pidato diambil dari buku latihan pidato dan juga boleh dari internet. Sistematika isi pidato adalah pembukaan, isi, dan terakhir penutup, materi dalam berpidato harus berisi tentang ilmu pengetahuan.

Dari penjelasan tentang pelaksanaan ekstrakurikuler muhadharah di Madrasah Ibtidaiyah Ruhul Amin Temon Sawoo Ponorogo di atas dapat peneliti pahami bahwa kegiatan ekstrakurikuler muhadharah adalah ekstrakurikuler yang wajib diikuti oleh semua siswa. Dilihat dari proses pelaksanaan ekstrakurikuler muhadharah di MI Ruhul Amin sudah berjalan dengan baik dan lancar.

Strategi adalah perencanaan dan manajemen untuk mencapai tujuan, strategi tidak hanya berfungsi sebagai peta jalan yang hanya menunjukan arah saja, melainkan harus menujukan bagaimana tehnik (cara) oprasionalnya. Secara khusus, strategi adalah "penempaan" misi perusahaan, penetapan sasaran organisasi dengan mengingat kekuatan eksternal dan internal, perumusan kebijakan dan strategi tertentu untuk mencapai sasaran dan memastikan implementasinya secara tepat, sehingga tujuan dan sasaran utama organisasi akan tercapai.

Strategi

muhadharah dalam melatih kemampuan public speaking di
Madrasah Ibtidaiyah Ruhul Amin Temon Sawoo Ponorogo adalah dengan pembuatan jadwal muhadharah, membuat dan mengoreksi teks pidato, pemilihan tempat muhadharah secara berubah-ubah, pengikutsertaan kompetisi atau lomba. Dengan strategi perencanaan tersebut diharapkan tujuan dari kegiatan ekstrakurikuler muhadharah di MI Ruhul Amin dapat terlaksana secara maksimal.

Strategi yang digunakan dalam pelaksanaan muhadharah dalam melatih kemampuan public speaking siswa di MI Ruhul Amin adalah dengan strategi hafalan juga dengan membaca naskah/teks pidato. tergantung dengan tingkat kelas siswa tersebut. Untuk kelas empat masih boleh untuk membaca teks namun untuk kelas lima minimal pembukaan harus hafal apalagi untuk kelas enam harus hafal di luar kepala. Untuk audiens harus mematuhi tata tertib yang ada seperti mendengarkan dan tidak ramai sendiri ketika kegiatan sedang berlangsung, jika ada yang melanggar maka akan diberikan hukuman berupa istimbat. Dengan ketentuan itu diharapkan siswa bisa terbiasa untuk berbicara di depan orang lain.

Dari penjelasan di atas peneliti menyimpulkan bahwa strategi kegiatan ekstrakurikuler muhadharah dalam melatih kemampuan public speaking di MI Ruhul Amin adalah suatu penerapan yang diberikan kepada siswa untuk memudahkan bagaimana cara melaksanakan kegiatan muhadharah sesuai dengan peraturan yang sudah ada dan untuk mencapai tujuan dari kegiatan muhadharah tersebut, yaitu dapat melatih kemampuan public speaking siswa.

Dalam mencapai sebuah tujuan tentu tidak terlepas dari adanya 
hambatan-hambatan yang tidak sesuai dengan rencana. Faktor penghambat merupakan daya penghalang yang mempengaruhi capaian atau kesulitan untuk mencapai tujuan. Dalam kegiatan ekstrakurikuler muhadharah di MI Ruhul Amin terdapat beberapa hambatan di antaranya adalah kurangnya minat siswa dalam pelatihan muhadharah, kurang percaya diri, sarana yang kurang lengkap, karakter siswa yang berbeda-beda dan juga penyampaian materi yang monoton.

Dengan adanya hambatanhambatan tersebut yang terdapat dari berbagai aspek tentu akan mengakibatkan tidak tercapainya tujuan sehingga lembaga atau madrasah perlu memikirkan bagaimana kedepannya siswa dapat menjalankan kegiatankegiatan tersebut dengan maksimal dan sesuai dengan apa yang diharapkan. Di dalam kegiatan ekstrakurikuler muhadharah perlu adanya bentukbentuk kegiatan menarik, menyenangkan, teratur, dan juga kadang-kadang dilaksanakan diluar ruangan agar anak-anak tidak merasa bosan. Dengan demikian perlu adanya saling komunikasi antara pembimbing dengan kepala madrasah agar hambatan-hambatan dari kegiatan ekstrakurikuler muhadharah dapat teratasi.

Demi tercapainya sebuah tujuan dari setiap kegiatan perlu adanya faktorfaktor yang mendukung kegiatan tersebut. Menurut observasi dan wawancara yang peneliti lakukan di MI Ruhul Amin terdapat beberapa faktor pendukung yaitu, ekstrakurikuler muhadharah dilaksanakan secara rutin, adanya evaluasi belajar, adanya hukuman bagi siswa yang melanggar aturan dan pembimbing yang memiliki kualitas. Setiap sesuatu yang dikerjakan secara terus menerus pasti akan menjadi sebuah kebiasaan. Begitu pula dengan ekstrakurikuler muhadhrah bila dilaksanakan dan diikuti secara rutin pasti akan melatih kemampuan public speaking. Siswa akan menjadi terbiasa untuk berbicara di depan umum melatih tanggungjawab serta kedisplinan. Setiap kegitan sudah pasti perlu adanya evaluasi, evaluasi adalah suatu usaha untuk mengukur dan memperbaiki suatu kegiatan yang dilaksanakan. Begitu juga dengan ekstrakurikuler muhadharah pelru dievaluasi agar tujuannya bisa tercapai. Pembimbing muhadharah juga sangat berperan penting dalam tercapainya tujuan. Dengan pembimbing yang mempunyai kompeten diharapkan dapat membantu siswa untuk melatih kemampuan public speaking mereka.

Dari penjelasan tersebut dapat peneliti simpulkan bahwa setiap suatu kegiatan pasti terdapat faktor pendukung maupun penghambat. Dua hal tersebut pasti ada dalam setiap hal atau kegiatan. Faktor penghambat harus dievaluasi oleh pembimbing dan kepala madrasah agar dapat dihilangkan atau paling tidak diminimalisir. Dan faktor pendukung yang ada adalah sebagia penguat untuk menghilangkan penghambat-penghambat yang ada dalam kegiatan ekstrakurikuler muhadharah dan juga sebagai pendukung untuk tercapainya dari tujuan ekstrakurikuler muhadharah itu sendiri.

\section{SIMPULAN}

Dari hasil penelitihan yang dilakukan di Madrasah Ibtidaiyah Ruhul Amin dapat disimpulkan bahwa strategi ekstrakurikuler muhadharah dalam melatih kemampuan public speaking 
siswa di MI Ruhul Amin sudah berjalan dengan baik bisa dilihat dari:

1. Ekstrakurikuler muhadharah di MI Ruhul Amin dilaksanakan rutin setiap hari sabtu pukul 11.00-12.00 WIB yang diikuti oleh semua siswa dari kelas satu sampai dengan kelas enam. Acara dimulai dari pembukaan, pembacaan ayat suci AlQur'an, menyanyikan mars madrasah, pidato, hiburan, sambutan dan penutup. Pelaksanaan muhadharah dilakukan dengan tiga bahasa yaitu bahasa Indonesia, bahasa Inggris, bahasa Arab, pembimbing memilih petugas pada waktu sambutan. Tujuan dari ekstrakurikuler muhadharah adalah siswa diharapkan untuk lebih berani tampil di depan umum atau paling tidak dapat melatih kemampuan berkomunikasi.

2. Strategi yang digunakan dalam ekstrakurikuler muhadharah adalah

a) pembuatan jadwal muhadharah b) membuat dan mengoreksi teks pidato c) pemilihan tempat muhadharah secara bergantian d) pengikutan kompetisi atau lomba. Dalam pelaksanaanya metode yang digunakan adalah metode hafalan juga dengan membaca teks tergantung tingkat kelas. Dengan strategi tersebut diharapkan dapat membantu siswa untuk melatih kemampuan public speaking mereka.

3. Faktor penghambat kegiatan ekstrakurikuler muhadharah di MI Ruhul Amin antara lain a) kurangnya minat siswa dalam pelatihan muhadharah b) kurang kuatnya mental siswa c) sarana yang kurang lengkap d) karakter siswa yang berbeda-beda dan e) penyampaian materi yang monoton. Untuk faktor pendukungnya antara lain ekstrakurikuler

muhadharah dilaksanakan secara rutin b) adanya evaluasi belajar c) adanya hukuman bagi siswa yang melanggar aturan dan d) pembimbing yang memiliki kualitas.

\section{DAFTAR PUSTAKA}

Adela, Loviana. "Strategi Pelatihan Muhadharah Terhadap

Kemampuan Berdakwah Santri Pondok Pesantren Darul Ulya Iringmulyo Kecamatan Metro Timur Kota Metro Lampung.” IAIN Metro, 2019.

Ainiyah, Nur. "PEMBERDAYAAN KETERAMPILAN RETORIKA DAKWAH SANTRI PONDOK PESANTREN MIFTAHUL ULUM PANDEAN WONOREJO BANYUPUTIH SITUBONDO." AsSidanah: Jurnal Pengabdian Masyarakat 1, no. 2 (2019): 141-70.

Ati, Azimah Kusuma. "Peran Muhadharah Dalam Melatih Kemampuan Komunikasi Siswa Di Mi Ma'arif Polorejo Babadan Ponorogo." IAIN Ponorogo, 2020.

Dian, Wahyu Binti Nurohmah. "PERAN GURU DALAM MENINGKATKAN PERCAYA DIRI SISWA MELALUI KEGIATAN EKSTRAKURIKULER MUHADHARAH DI MI MA'ARIF AL ISHLAH KALISAT BUNGKAL PONOROGO." IAIN PONOROGO, 2018.

Fathoni, Tamrin, Asfahani Asfahani, Erfa Munazatun, and Lilis Setiani. "Upaya Peningkatan Kemampuan Public Speaking Pemuda Sragi Ponorogo." Amalee: Indonesian Journal of Community Research and Engagement 2, no. 1 (2021): 23-32.

Firmansyah, Noris. "Efektivitas Kegiatan Ekstrakurikuler Muhadharah Dalam Pembentukan Rasa Percaya 
Diri Peserta Didik MA Fadllillah Tambak Sumur Waru Sidoarjo." UIN Sunan Ampel Surabaya, 2017.

Nugrahani, Farida. Metode Penelitian Kualitatif Dalam Penelitian

Pendidikan Bahasa. Cakra Book. Solo, 2014.

Nurcandrani, Prita S, Bunga Asriandhini, and Ade Tuti Turistiati. "Pelatihan Public Speaking Untuk Membangun Kepercayaan Diri Dan Keterampilan Berbicara Pada AnakAnak Di Sanggar Ar-Rosyid Purwokerto." Jurnal Abdi MOESTOPO 3, no. o1 (2020): 27-32. Priyadi, Unggul. "MEMBANGUN KEPERCAYAAN DIRI ANAK MELALUI PELATIHANPUBLIC SPEAKING GUNA PERSIAPKAN GENERASI BERKARAKTER.” Asian Journal of Innovation and Entrepreneurship 2, no. 02 (2013): 88-93.

Purwanti, Lina. "Problematika

Peningkatan Kecerdasan Linguistik Siswa Dalam Kegiatan Muhadharah (Studi Kasus Di MI Ma'arif Polorejo Ponorogo).” IAIN Ponorogo, 2020. Rumpoko, Hadi. Panduan Pidato Luar
Biasa. Yogyakarta: Mega Books, 2012.

Sholihah, Rizki Amalia. "Metode Suggestopedia Dengan Teknik Bermain Peran Atau Role Playing Dalam Pembelajaran Keterampilan Berbicara Bahasa Indonesia Siswa Sekolah Dasar." Al-Adabiya: Jurnal Kebudayaan Dan Keagamaan 10, no. 1 (2017): 1-24.

_-_. "Praktik Pembelajaran Keterampilan Berbicara Di Masa Pandemi Covid-19." NATURALISTIC: Jurnal Kajian Penelitian Pendidikan Dan Pembelajaran 5, no. 1 (2020): 705-17. https://doi.org/10.35568/naturalisti c.v5i1.977.

Srinivas, Parupalli Rao. “The Importance of Speaking Skills in English Classrooms." Alford Council of International English $\mathcal{E}$ Literature Journal(ACIELJ) Vol 2, no. Issue 2 (2019): 18.

Sugiyono. Metode Penelitian Pendidikan: (Pendekatan Kuantitatif, Kualitatif $\operatorname{Dan} R \mathcal{E} D)$. Bandung: Alfabeta, 2008.

Zuhri, Saifudin. Public Speaking. Yogyakarta: Graha Ilmu, 2010. 